\title{
Neuroenology: how the brain creates the taste of wine
}

\author{
Gordon M Shepherd
}

\begin{abstract}
Flavour science is concerned with the sensory appreciation of food. However, flavor is not in the food; it is created by the brain, through multiple sensory, motor, and central behavioral systems. We call this new multidisciplinary field "neurogastronomy." It is proving useful in integrating research findings in the brain with the biomechanics of generating food volatiles and their transport through retronasal smell. Recent findings in laboratory animals and in humans give new insights into the adaptations that have occurred during evolution that give humans an enhanced flavor perception. This process will be illustrated by an analysis of how the brain creates the taste of wine. The successive stages of the biomechanics of movement of the ingested wine and transport of the released volatiles will be correlated with activation of the multiple brain mechanisms, apparently engaging more of the brain than any other human behavior. These stages include the initial cephalic phase, visual analysis, ingestion, formation of the wine perceptual image, formation of the wine perceptual object, swallowing, and post-ingestive effects. This combined biomechanic and brain mechanism approach suggests a new discipline of "neuroenology (neuro-oenology)," adding to the contributions that science can make to the enhanced quality and appreciation of wine.
\end{abstract}

Keywords: Wine, Retronasal smell, Wine image, Wine perceptual object, Fluid mechanics

Interest in food flavors is expanding rapidly, driven by a widening interest in food and concerns about the rising incidence of obesity and diseases related to unhealthy eating. While most interest is focused on the food, its composition, and the perceptions that it brings forth (see other contributions to this symposium), this has left large gaps of knowledge about the specific brain systems that create the perceptions. This approach to flavor through brain mechanisms has been termed neurogastronomy [1]. Here we outline some of the principles that are the basis for this new approach and then use wine tasting as an example.

\section{Some principles of neurogastronomy}

To begin, flavor is not in the food; it is created from the food by the brain [2]. There is a clear analogy with other sensory systems. In vision, for example, color is not in the wave lengths of light; color is created from the wave lengths by the neural processing circuits in the visual

Correspondence: gordon.shepherd@yale.edu

Department of Neurobiology, Yale University School of Medicine, 333 Cedar Street, New Haven, CT 0651, USA pathway; these include center-surround interactions for color-opponent mechanisms [3]. Similarly, pain is not in the agents that give rise to it, such as a pin or a toxin; pain is created by the neural processing mechanisms and circuits in the pain pathway, together with central circuits for emotion [4].

Improved understanding of these mechanisms should give ultimate insight into the "qualia" of sensory perception. Flavour is an attractive system for contributing to these insights.

Second, flavor is a multi-modal sensation. It is multisensory, involving all the sensory systems of the head and upper body [5]. This is nicely demonstrated in a quote [1] attributed to the famous chef Paul Bocuse:

The ideal wine ... satisfies perfectly all five senses: vision by its color; smell by its bouquet; touch by its freshness; taste by its flavor; and hearing by its "glou-glou".

At the same time, flavor is multimotor, involving all the relevant motor systems. These include the obvious muscle systems of the tongue, jaw, and cheeks, critical 
for manipulating the food and drink in the mouth [6]. Recent research suggests that the movements of the tongue in manipulating food in the mouth are more complex than the movements used in creating the sounds of speech [7]. The motor systems also include those of the neck involved in swallowing, plus those in each sensory system (inner ear, eye muscles), plus the diaphragm and chest and pelvic muscles involved in breathing. They also include the glands for producing saliva for solubilizing and initiating digestion the food in the mouth. Flavor is therefore special in being always an active sense, with motor systems essential to activating the sensory pathways and central brain systems.

Third, much of flavor is due to retronasal smell, that is, smell that occurs when we are breathing out, to carry the volatiles from the mouth to the nasal cavity. This can truly be called our unknown sense. It was early recognized [8] that smell is a dual sense, reflecting the fact that odor stimuli can be delivered by both orthonasal (sniffing in) and retronasal (breathing out) routes. Most of what we know about smell, both in humans and laboratory animals, comes from studies of orthonasal smell. Research on retronasal smell is relatively recent [9-11].

There is evidence going back to Victor Negus [12] that most mammals have a relatively long palate and nasopharynx for retronasal smell, in contrast to humans who have a relatively short palate that places the back of the mouth, where volatiles from the mouth are produced, relatively close to the nasal cavity for sensing by smell. Humans therefore appear to be adapted for retronasal smell and flavor.

Fourth, we are normally entirely unconscious of the retronasal contribution to flavor. The touch of the food in the mouth and the conscious sensations of the basic tastes emanating from the tongue "capture" our awareness of the food and refer all other sensations, including retronasal smell, to the mouth [2]. Flavor therefore has the quality of an illusion. This makes flavor vulnerable to many influences, as is well recognized by food producers in formulating and promoting their foods. Food producers spend millions on research to use the sensory illusions to influence our choices of food, in our homes as well as in the supermarket and the school cafeteria [13]. We therefore need a better understanding of retronasal smell in order to develop public policies based on better understanding of brain mechanisms that can lead to eating healthier food.

Fifth, as already indicated, we must keep in mind the underlying principle that "Nothing in biology makes sense except in the light of evolution" [14]. This is essential in understanding how flavor perception and its associated sensory, motor, and central behavioral systems have been built into humans over the past million years and are the basis for current eating habits. Wrangham has hypothesized that the control of fire by early humans enabled them to invent cooking, which increased the energy in food, thus enabling the larger brains of Homo sapiens [15]. Cooking would obviously have also enhanced the flavors of the food. From this perspective, retronasal smell and flavor may thus have played a central role in how we became human. The adaptations of the human head for playing this role have been discussed in detail by Lieberman [7].

\section{A new vision for flavor science}

It is obvious from the range of these principles that brain mechanisms in flavor perception have far reaching ramifications in modern society. It has been argued that this requires a much enlarged framework for understanding flavor. As discussed in a recent conference [16], this new all-embracing vision for a science of food and its flavors begins with the principle cited that biology makes sense only in the light of evolution. A corollary for the neuroscientist is "Nothing in the brain makes sense except in the light of behavior". The multiple neural mechanisms involved in producing flavor include sensory, motor, cognitive, emotional, language, pre- and post-ingestive, hormonal, and metabolic. It can be claimed that more brain systems are engaged in producing flavor perceptions than in any other human behavior. These mechanisms are in play from conception through old age. Understanding them requires research on both humans and laboratory animals. In addition to insights into normal function, this research is needed for dealing with clinical disorders, ranging from obesity to Parkinson's, and including dental medicine. Food producers carry out their own research on the brain mechanisms to draw consumers to products with attractive flavors but in too many cases with unhealthy consequences; the public needs to be as well informed about the brain mechanisms so that together more healthy foods can be produced and consumed. Food activists play roles in pressing for sustainable diets, anti-poverty policies, responsible agriculture; and preventing the consequences of climate change. Finally, new initiatives in flavor research are urgently needed with funding for broad attacks that will benefit nutrition and public health.

\section{Mechanisms for flavor images and flavor biomechanics}

In order to understand the multisensory integration that underlies flavor perception, we need to begin with how the brain represents the sensory world. Most sensory systems use neural space to represent their stimuli. This is most obvious in the somatosensory system, where the body surface is represented across a strip of cortex as a "homunculus". It is also obvious in vision, where the external visual field is represented by the visual field in the primary visual cortex. Less obvious is the auditory system. 
How is sound frequency, which has no spatial property, represented in the brain? Research has shown that frequency is represented by a frequency map laid out across primary auditory cortex. The map is a simple progression of frequency for the cat, but a much more elaborate progression for the bat which has an enlarged area for the frequency it uses for locating prey [17].

Olfactory stimuli, in the form of different molecules, also have no spatial property. What are the neural mechanisms by which the information carried in an odor molecule is represented in the brain? In rodents, it was early established that stimulation with a given type of odor molecule elicits a pattern of activity in the glomerular layer of the olfactory bulb [18]. We called these "odor maps"; they are also called odor images or "smell images". A critical finding was that although the patterns for different odors are extensive and overlapping, they are different for different molecules [19], even if they differ by only a single carbon atom and its two hydrogens [20]. Further behavioral experiments have shown that rodents can easily distinguish these fine differences [21], a sensitivity far greater than that for antibody-antigen recognition in the immune system.

Breakthrough experiments identified the odor receptor molecules [22] and showed that subsets of receptor cells expressing the same receptor gene project to differing sites in the glomerular layer, thus supporting the concept that space plays a role in encoding odor molecules. We are constructing computational models in three dimensions to gain further insight into how these images are formed within the olfactory bulb [23]. Further processing transforms the odor images in the olfactory bulb, representing the information in the odor molecules, to "odor objects" in the olfactory cortex, which are in a form that can be integrated by the brain into odor perception [24].

These results have been revealed by experiments using orthonasal smell. This scheme is believed in general to apply to the neural processing mechanisms in retronasal smell. However, the dramatic difference is that when retronasal smell is activated by volatiles released from the back of the mouth during exhalation, all the associated systems involved in flavor perception are also activated. The question then arises: How is this array of systems coordinated? The mechanisms of activation are presently little understood, beyond what has already been mentioned about the complex movements of the tongue and the equally complex mechanisms of swallowing, coordinated with respiration.

Activation of the multimodal systems of flavor can be seen to be tightly linked to the movement of the food and drink through the mouth together with the movements of muscles and air during respiration. We can call these motor events the biomechanics of flavor. The biomechanics of the movement of air past the back of the mouth involves more specifically a subset of engineering problems that fall under the category of dynamic fluid mechanics. This approach has revealed complex flow patterns of air through the nasal cavity during orthonasal [25-27] smell. The challenge now is to do the same for the flow patterns of air through the oro- and nasopharynx during retronasal smell.

\section{Neuroenology (neuro-oenology): from biomechanics to the taste of wine}

Building on the principles discussed above, let us use wine tasting as a specific example.

Hundreds of books have been written about wine tasting $[28,29]$. Most focus on the grapes, the vintages, and the techniques of tasting. Most include comments on the roles that the different senses play but few on recent studies of their pathways and mechanisms in the brain.

Here we wish to contribute to building a science of wine tasting by approaching the wine from the perspective of the brain. For this, we need to unite the biomechanics of movement of wine through the mouth and the movement of air through the oro- and nasopharynx into the nasal cavity, with the activation of, and control by, the multimodal brain systems. Recently, at a symposium on wine, I drew together these aspects to use wine tasting as an example of neurogastronomy and will use it here to suggest some principles that may be called neuroenology (or neuro-oenology in British spelling).

We start with the key role proposed for retronasal smell. What is the proof that the retronasal pathway is open during tasting of the wine? Fluoroscopic observation has been made of the head and neck during ingestion of liquid; an example is available on YouTube (https://www.youtube. $\mathrm{com} /$ watch? $\mathrm{v}=\mathrm{umnn} A 50$ IDIY29). As can be seen, the nasopharynx is clearly open with the fluid in the mouth and closes when swallowing. This can be easily confirmed by personal experience; with wine in the mouth, breathing in and out occurs while sensing of the taste of the wine occurs, which is shut off when swallowing.

We are currently carrying out a quantitative analysis of this process, involving the biomechanics of wine in the mouth and fluid dynamics of the volatiles in the airway, which is still at an early stage. However, at this point, it is possible to suggest the main steps at the core of the wine tasting experience.

An animation was shown at the meeting to illustrate these events. Table 1 summarizes the most important steps.

The first step (cephalic phase) occurs entirely in the head, consisting of the accumulated experience of the taster with wine in general and anticipation of this wine or wine tasting in particular. The expected flavor of the wine is thus due entirely to vision and to the imagination. The wine is then poured and preliminary analysis carried out of it in the glass. Closer visual inspection strongly influences the expected flavor ("We eat first with our eyes" [30]). The aroma (bouquet) is the first encounter 
Table 1 Brain and biomechanics stages in wine tasting

\begin{tabular}{ll}
\hline Brain systems & Biomechanics \\
\hline Cephalic phase (vision) & \\
Preliminary analysis (vision) & Orthonasal smell \\
Ingestion & Tongue, exhalation, retronasal smell \\
Initial analysis & Tongue, exhalation, retronasal smell \\
Forming the wine perceptual image & Tongue, exhalation, retronasal smell \\
Forming the wine flavor object & Tongue, exhalation, retronasal smell \\
Swallowing & Automatic motor action \\
Post-swallowing & Exhalation, retronasal smell \\
\hline
\end{tabular}

with the olfactory sense, due to orthonasal smell acting together with vision.

With ingestion, the wine is placed carefully in the mouth for maximum exposure to the senses. Initial analysis occurs by each of the major internal senses: touch and mouth-feel, taste, retronasal smell, and hearing. Touch is critical in locating the wine in the mouth; as with food, it fools the brain into assuming that all the "taste" of the wine comes from the mouth. The motor systems for saliva and muscle movement of the tongue, cheek, and jaw are activated. Thus, like food, wine taste is also an active perception. Each sense initially forms its own sensory image.

Simultaneous activation of the multiple sensory systems spreads from the primary to the surrounding association areas. Their common action begins to form what can be called the wine perceptual image. This combined image is conscious, except that it contains the illusion that its olfactory part is coming from the mouth and is part of "taste". Experienced tasters enhance the taste by breathing in through the lips to aerate the wine in the mouth, although the effect does not reach the nose until breathing out through the nasopharynx. The taste is also enhanced by expert movements of the tongue to move the wine completely over all the taste buds of the tongue and pharynx. As mentioned, these movements are more complex than the tongue movements in forming speech. The movements also mix the wine with the saliva. Working against these mechanisms for enhancement is sensory adaptation, which occurs at all levels of the sensory pathways, from the receptors and their second messenger systems to the successive synaptic relays on the way to the cortex.

As processing in the sensory pathways continues, the images which were formed to represent the external sensory stimuli are transformed into central representations of the entire flavor object, i.e., in this case, the wine flavor object. That is, the images in the languages of the senses are transformed into objects in the language of the brain. In addition to the sensory pathways for discrimination, central behavioral systems are engaged, also in the language of the brain. Memory systems mediate recognition. Emotion systems mediate feelings. Dopamine systems mediate reward. Motivation systems calculate continuance of drinking. And most important for humans, language systems enable categorization that can be formulated by ourselves and communicated to others. Retronasal smell continues to flood the olfactory receptors with volatiles from the wine in the mouth. This maximum activation of flavor systems is depicted in Figure 1.

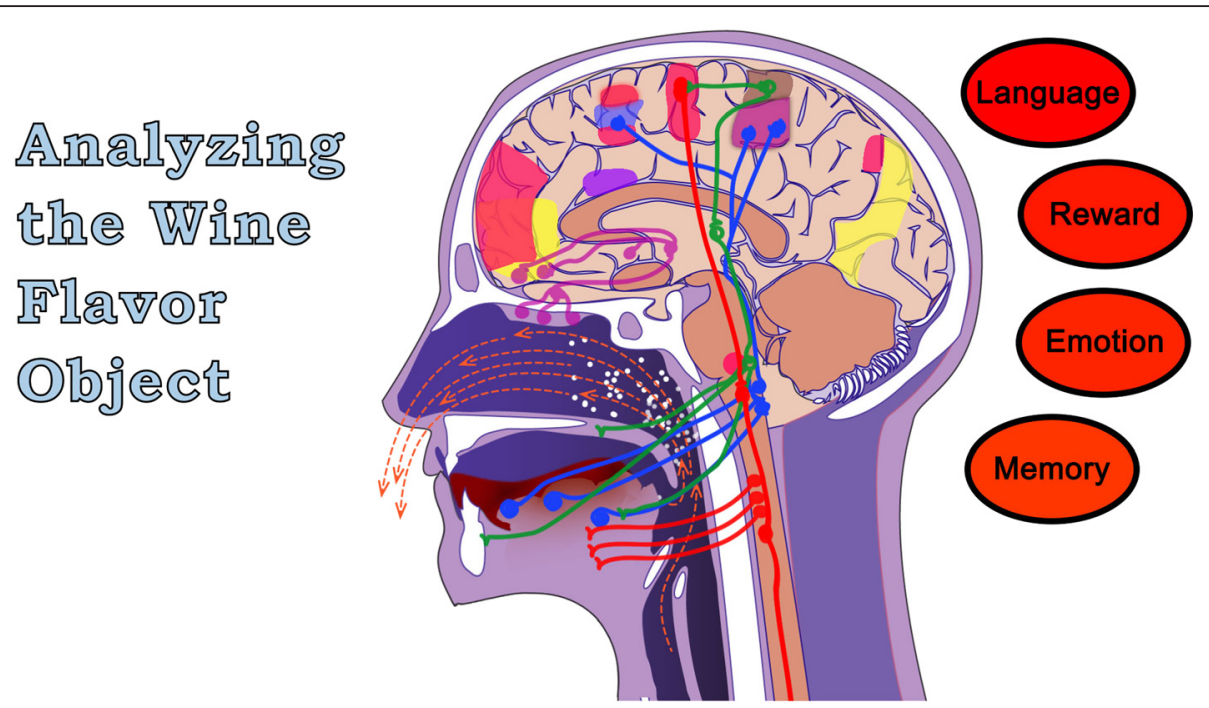

Figure 1 Analyzing the wine flavor object. Summary of activation of flavor systems related to wine tasting. Sensory pathways include touch, taste, olfaction, visual cortex (audition not shown). Motor pathways include mouth: tongue, cheek, jaw, glands producing saliva; pharynx; lungs for inhalation and exhalation. Ellipses represent activation of central brain systems for memory, emotion, motivation, reward, and language. Adapted from [31]. 
For many people, this represents the peak of the wine tasting experience. However, there is one more step. The prefrontal cortex decides when all the systems have reached their culmination, and the conscious decision is made to terminate by swallowing. The soft palate closes to prevent aspirating wine into the nasopharynx, the epiglottis closes to prevent it entering the trachea, and the complex systems of muscles of the tongue, pharynx, neck, and lung carry out swallowing automatically. It is one of the most complex behaviors in mammalian life.

But the sensory stimulation of the wine tasting is not yet over. In the post-swallowing phase, the wine coating the pharynx still is carried to the smell receptors in the nose by retronasal smell, providing the "longueur on bouche" ("length in the mouth"). Together with the lingering activity in the systems for memory, emotion, and motivation, it contributes to the final conscious evaluation of the wine. In addition, the post-ingestive period is characterized by metabolic effects of the wine in the gut [32]. In the case of studies of this period during food consumption, there is increasing interest in these actions on isolated taste buds and on the metabolic effects of carbohydrates that contribute to obesity. In the case of wine, the alcohol content has actions on central systems for craving leading to inebriation [33], reminding us that, as with so many things in life that give us pleasure, in excess, wine is also a potential drug of abuse.

In summary, the stages in wine tasting have traditionally been characterized by the tasters. Increasing knowledge of brain mechanisms and the associated biomechanics of the wine in the mouth and the volatiles in the airway gives a new enlarged framework for a deeper understanding of this most complex experience of flavor among all of human foods.

\section{Competing interests}

The author declares that he has no competing interests.

\section{Acknowledgements}

For valuable experience in wine tasting, I am indebted to Jean-Claude Berrouet, Petrus; Sandrine Garbay, Château d'Yquem; Marilisa Allegrini, Amarone Valpolicella; Ann Noble, University of California Davis; Jean-Didier Vincent, Universities of Bordeaux and Paris; Pierre-Marie Lledo, Institut Pasteur; Terry Acree, Cornell University; and Albert Scicluna, Les Domaines qui montent. Our research is supported by the National Institute for Deafness and Other Communicative Disorders within the National Institutes of Health.

Received: 19 December 2014 Accepted: 30 December 2014

Published online: 02 March 2015

\section{References}

1. Shepherd GM. Neurogastronomy. How the brain creates flavor, and why it matters. New York: Columbia University Press; 2012.

2. Small DM. Flavor is in the brain. Physiol Behav. 2012;107(4):540-52.

3. Daw ND. How vision works: the physiological mechanisms behind what we see. New York: Oxford University Press; 2012.

4. Lenz FA, Casey KL, Jones EG, Wlilis WD. The human pain system: experimental and clinical perspectives. Cambridge, UK: Cambridge University Press; 2010.

5. Spence C. Multisensory flavour perception. Curr Biol. 2013;23(9):R365-369.
6. Amat J-M, Vincent J-D. L'art de parler la bouche pleine. Paris: La Presqu'ile; 1997.

7. Lieberman DE. Evolution of the human head. Cambridge MA: Harvard University Press; 2011.

8. Rozin P. "Taste-smell confusions" and the duality of the olfactory sense. Percep Psychophys. 1982;31(4):397-401.

9. Pierce J, Halpern BP. Orthonasal and retronasal odorant identification based upon vapor phase input from common substances. Chem Senses. 1996;21(5):529-43.

10. Bojanowski V, Hummel T. Retronasal perception of odors. Physiol Behav. 2012;107:484-7.

11. Gautam SH, Verhagen JV. Retronasal odor representations in the dorsal olfactory bulb of rats. J Neurosci. 2012;32(23):7949-59.

12. Negus V. Comparative anatomy and physiology of the nose and paranasal sinuses. London: E \& S Livingstone; 1958.

13. Moss M. Salt sugar fat: how the food giants hooked us. New York: Random House; 2014.

14. Dobzhansky T. Biology, molecular and organismic. Am Zool. 1964;4:443-52.

15. Wrangham R. Catching fire: how cooking made us human. New York: Basic Books; 2009

16. Shepherd GM. A new vision for the science of human flavor perception. Front. Integr. Neurosci. Conference Abstract: Science of Human Flavor Perception.2015; doi: 10.3389/conf.fnint.2015.03.00010.

17. Suga N. Specialization of the auditory system for reception and processing of species-specific sounds. Fed Proc. 1978;37:2342-54.

18. Stewart WB, Kauer JS, Shepherd GM. Functional organization of rat olfactory bulb analysed by the 2-deoxyglucose method. J Comp Neurol. 1979;185(4):715-34.

19. Xu F, Liu N, Kida I, Rothman DL, Hyder F, Shepherd GM. Odor maps of aldehydes and esters revealed by functional MRI in the glomerular layer of the mouse olfactory bulb. Proc Natl Acad Sci U S A. 2003;100(19):11029-34.

20. Laska M, Joshi D, Shepherd GM. Olfactory sensitivity for aliphatic aldehydes in CD-1 mice. Behav Brain Res. 2006:167(2):349-54.

21. Buck $L$, Axel R. A novel multigene family may encode odorant receptors: a molecular basis for odor recognition. Cell. 1991;65(1):175-87.

22. Migliore M, Cavarretta F, Hines ML, Shepherd GM. Distributed organization of a brain microcircuit analyzed by three-dimensional modeling: the olfactory bulb. Front Com Neurosci. 2014;8:50.

23. Wilson DA, Stevenson RJ. Learning to smell: olfactory perception from neurobiology to behavior. Baltimore, MD: The Johns Hopkins University Press; 2006

24. Yang GC, Scherer PW, Mozell MM. Modeling inspiratory and expiratory steady-state velocity fields in the Sprague-Dawley rat nasal cavity. Chem Senses. 2007;32(3):215-23.

25. Lawson MJ, Craven BA, Paterson EG, Settles GS. A computational study of odorant transport and deposition in the canine nasal cavity: implications for olfaction. Chem Senses. 2012;37(6):553-66.

26. Settles GS. Sniffers: fluid-dynamic sampling for olfactory trace detection in nature and homeland security - the 2004 freeman scholar lecture. J Fluids Engin. 2005;127:189-218.

27. Jackson RS. Wine tasting: a professional handbook. 2nd ed. Amsterdam: Elsevier; 2009.

28. Baldy MW. The university wine course. San Francisco CA: The Wine Appreciation Guild; 2009.

29. Delwiche JF. You eat with your eyes first. Physiol Behav. 2012;107(4):502-4

30. Sclafani A. Gut-brain nutrient signaling. Appetition vs. Satiation. Appetite. 2013;71:454-8

31. Aleejandro G. Animation. http://medicine.yale.edu/lab/shepherd/projects/ neuroenology.aspx

32. Volkow ND, Wang GJ, Baler RD. Reward, dopamine and the control of food intake: implications for obesity. Trends Cogn Sci. 2011;15(1):37-46.

33. Shepherd GM. Smell images and the flavour system in the human brain. Nature. 2006;444(7117):316-21. 